\title{
Influence of Glassy or Rubbery State on the Antimicrobial Activity of Chitosan-gelatin Films
}

\author{
Daniela Celis Cofré ${ }^{1}$, Manuel Ignacio Azócar ${ }^{2,3}$, Javier Enrione ${ }^{1,3}$, Maritza Páez ${ }^{2,3}$ \& Silvia Matiacevich ${ }^{1,3}$ \\ ${ }^{1}$ Departamento de Ciencia y Tecnología de los Alimentos, Facultad Tecnológica, Universidad de Santiago de \\ Chile, Santiago, Chile \\ ${ }^{2}$ Departamento de Química de los Materiales, Facultad de Química y Biología, Universidad de Santiago de Chile, \\ Santiago, Chile \\ ${ }^{3}$ Soft Matter Research and Technology Center SMAT-C, Universidad de Santiago de Chile, Santiago, Chile \\ Correspondence: Silvia Matiacevich, Departamento de Ciencia y Tecnología de los Alimentos, Facultad \\ Tecnológica, Universidad de Santiago de Chile, Avenida Ecuador 3769 (7190200), Estación Central, Santiago, \\ Chile. Tel: 56-2718-4517. E-mail: silvia.matiacevich@usach.cl
}

\author{
Received: September 27, 2012 Accepted: October 11, 2012 Online Published: October 29, 2012 \\ doi:10.5539/jfr.v1n4p184 \\ URL: http://dx.doi.org/10.5539/jfr.v1n4p184
}

\begin{abstract}
The aim was to study if the antimicrobial activity of chitosan incorporated into edible films based on gelatin could be affected by the molecular mobility (glassy or rubbery state) of the matrix. Films were obtained from film-forming suspensions (FFS) of bovine and salmon gelatins $(7 \% \mathrm{w} / \mathrm{w})$ and chitosan $(0 ; 0.25 ; 0.5 ; 1 \% \mathrm{w} / \mathrm{w})$ equilibrated at 33\% y $85 \%$ of relative humidities. Antimicrobial properties against Escherichia coli, Listeria monocytogenes and Salmonella thyphimurium were determined. The results showed that both FFS and films had antimicrobial effects related to chitosan concentration. This besides depended on their glass and rubber film state, being in the initially glassy state for salmon $66 \%$ higher than bovine in comparison to the rubbery state ( $8 \%$ ). This was mainly due to the highest moisture uptake $(1.82 \pm 0.02 \%$ water absorbed $/ \mathrm{min})$ for glassy state. Therefore, the molecular mobility of the matrix film affected the antimicrobial activity of chitosan in chitosan-gelatin films.
\end{abstract}

Keywords: chitosan, films, gelatin, molecular mobility, antimicrobial activity

\section{Introduction}

Gelatin-based films and coatings have been an interesting research field in recent years because they can improve the shelf-life of fresh foods and also because of their environmentally friendly properties (Cha \& Chinnan, 2004; Gomez-Estaca, López de Lacey, López-Caballero, Gómez-Guillén, \& Montero, 2010; Gomez-Estaca, Gómez-Guillén, Fernández-Martín, \& Montero, 2011). Interestingly, the increasing demand for gelatin from non-mammalian sources (by Halal and Kosher population) has promoted the use of other sources such as salmon gelatin which can be extracted from fish industry by-products (about 5\% in weight of the whole fish), making its production advantageous compared to other animal sources (Diaz, López, Matiacevich, Osorio, \& Enrione, 2011). The functionality of the coatings enhanced by including active compounds such as antimicrobials and antioxidants has been extensively studied (Devlieghere, Vermeulen, \& Debevere, 2004; Cha \& Chinnan, 2004; Pereda, Ponce, Marcovich, Ruseckaite, \& Martucci, 2011; Valencia-Chamorro, Palou, Del Rio, \& Pérez-Gago, 2011).

Chitosan is a natural linear polysaccharide derived from the deacetylation of chitin, an important component of crustacean shells, with available reactive amino and hydroxyl groups (Dutta, Dutta, \& Tripathi, 2004). Some advantages for food applications include, biodegradability, antimicrobial properties and no toxicity (Dutta, Tripathi, Mehrotra, \& Dutta, 2009; Kong, Chen, Xing, \& Park, 2010). Hydrogen bonds strongly stabilize its interand intra-molecular structure, making it soluble at low pH (<6.5) (Fan, Hu, \& Shen, 2009). Antimicrobial activity of chitosan has been shown against Gram-positive and Gram-negative bacteria, filamentous fungi, and yeasts (Kong et al., 2010). This activity is associated with the availability of $\mathrm{R}_{-} \mathrm{NH}_{3}{ }^{+}$groups that interact with the microbial cell membrane (Kong et al., 2010; Pereda et al., 2011). However, its functionality as antimicrobial agent depends on its molecular weight, degree of acetylation, concentration in solution and type of microorganism (Kong et al., 2010). Other important factors are direct environmental conditions, such as $\mathrm{pH}(<6.0)($ Qin et al., 2006) and ionic strength (Kong et al., 2010). Also it is important the presence of solutes susceptible to reaction 
with chitosan via electrostatic interaction and/or covalent bonds that can block the reactivity of the active amino groups present (Aider, 2010). In the case of intermediate and low moisture films, possible interactions between hydrocolloids and chitosan have been reported in the literature (eg. gelatin, carbohydrates), which might influence its antimicrobial effectiveness (Fernández-Saiz, Lagaron, \& Ocio, 2009; Kong et al., 2010; Pereda et al., 2011 ).

Previous publications have been focused mainly on developing films with improved mechanical and water-barrier properties to protect foods from drying and from exposure to light, by combining gelatin with other materials such as lipids, bioactive peptides, proteins, plasticizers and polysaccharides like gellan, chitosan and pectins (Cha \& Chinnan, 2004; Gómez-Estaca et al., 2011). However, the study of antimicrobial effects of edible films are reported mainly using the agar diffusion method (Pranoto, Rakshit, \& Salokhe, 2005; Dutta et al., 2009; Kong et al., 2010). It is important to note that several authors have reported limited diffusion of chitosan in films in agar medium, showing no inhibitory activity against microorganisms (Coma, 2002; Pranoto et al., 2005; Gómez-Estaca et al., 2010; Pereda et al., 2011). Therefore, the antimicrobial effect was principally studied by inhibitory halo or area on both former film solution and films put over agar plates without taking into account the kind of structural matrix or the moisture changes of films.

Coatings and films could be used to coat food surface. Coatings are obtained using film forming suspensions applied by immersion or spray and involve the formation of films directly on the surface of the product they are intended to protect. However, films are usually defined as a stand-alone thin layer, being the main use as testing structures for determination of physical properties. The structural matrix based on hydrocolloids changes (glassy or rubbery state) with temperature and moisture content during storage time could principally affect the molecular mobility of the film matrix. The antimicrobial efficiency could be depending on agent diffusion to agar plate, which also depends on their mobility or capacity to migrate within structural film matrix (Coma, 2002; Pranoto et al., 2005; Gómez-Estaca et al., 2010; Pereda et al., 2011).

Therefore, it is important to study if the antimicrobial effect of antimicrobial agents could be affected by the initial structural state (glassy or rubbery) of the edible film, due to the potential application as bioactive edible films for fresh foods, and in order to improve the knowledge about the initial structure state of the films before the contact to the food surface. Besides, it is important to study if the antimicrobial agent migrates from the film to the surface of the food or if it is effective against surface bacterial growth without the migration of the active agents to the food.

Regarding, the aim of this study was to evaluate the antimicrobial properties of chitosan incorporated into bovine and salmon gelatin films is affected by different molecular mobility (glassy and rubbery state).

The scientific relevance of this work was focused on a complex issue as molecular mobility from glass and rubber state of a protein film matrix and their possible interaction and participation on antimicrobial effect of other polymer such as chitosan. Besides, a novelty experimental design was performed to measure the bacterial viability percentage from films instead from liquid suspensions containing the antimicrobial agent.

\section{Materials and Methods}

This investigation included the preparation of gelatin-chitosan film forming suspensions (FFS) and films that were equilibrated to different moisture contents in order to obtain glassy and rubber matrix states. The glass transition temperature of the films was investigated in order to determine the structural mobility of the matrix (glass and rubbery states).

\subsection{Materials}

Salmon gelatin (SG) was extracted from the skin of Atlantic salmon (Salmo salar) from Chile's pacific coast, kindly provided by Salmon Oil S.A (Chile), using an acidic-alkaline extraction. Briefly, the skins were immersed in $0.1 \mathrm{M} \mathrm{NaOH}$ at $10^{\circ} \mathrm{C}$, stirred vigorously for $1 \mathrm{~h}$, and then immersed in $0.05 \mathrm{M}$ acetic acid for $1 \mathrm{~h}$ in order to eliminate impurities. The gelatin extraction process was carried out at $64^{\circ} \mathrm{C}$ at $\mathrm{pH} \sim 4.0$ for $3.5 \mathrm{~h}$. The supernatant was vacuum filtered and dried at $55^{\circ} \mathrm{C}$ for $24 \mathrm{~h}$. The salmon gelatin extracted was approximately $18-19 \%$ (g dry gelatin/100 g clean salmon skin), which is in agreement with the non-mammalian extraction yield reported in the literature (Jamilah \& Harvinder, 2002; Karim \& Bath, 2009).

Commercial type B Bovine Gelatin (BG) was provided by Rousselot (Bloom 220). The isoelectric point (IEP) was at $\mathrm{pH} \sim 5.0$ for both gelatins, calculated using the method described by Karim and Bhat (2009) and this value was in according to reported by Diaz et al. (2011).

Chitosan of low molecular weight $(50 \mathrm{kDa})$ and a deacetylation degree of $92 \%$ was purchased from Sigma Aldrich Chemicals Ltd. 
Mueller Hinton agar (Merck, Germany) and broth (DIFCO, France) were used for microbial analysis. Gram-negative bacteria (Escherichia coli (ATCC 25922), Salmonella typhimurium (ISP Ty2) and Gram-positive bacteria (Listeria monocytogenes (ISP 65-08) were kindly provided by the Departamento de Química de Materiales of the Facultad de Química y Biología of the Universidad de Santiago de Chile.

All other reagents used (acetic acid, $\mathrm{NaOH}$, etc.) were analytical grade.

\subsection{Film Forming Suspensions (FFS)}

The final concentration of solids in the film forming suspensions obtained was $7 \% \mathrm{w} / \mathrm{w}$. Bovine and salmon gelatins were dissolved in distilled water. The chitosan was previously dissolved in glacial acetic acid $(99.9 \% \mathrm{w} / \mathrm{w})$ (Winkler, Mexico) in a proportion of $1: 1(\mathrm{w} / \mathrm{w})$ and then gradually added to the gelatin suspensions to obtain a final concentration of chitosan of $0 ; 0.25 ; 0.5$ and $1 \%(\mathrm{w} / \mathrm{w})$. Each gelatin-chitosan suspension was stirred moderately at $50^{\circ} \mathrm{C}$ until complete dissolution. The $\mathrm{pH}$ of the resultant mixture was adjusted to 5.5 using $2 \mathrm{~N}$ $\mathrm{NaOH}$ (Mallinckrodt, Mexico). The pH of the FFS was measured with a pH-meter (Jenway, UK) using a liquid electrode model 3505 (Jenway, 924-001), after calibration with $\mathrm{pH} 4.0$ and 7.0 buffers, following Official Methods of Analysis standards (OMA, 1975). This $\mathrm{pH}$ (5.5) was considerer suitable to enable any potential in vitro antibacterial effects of the film forming suspension and/or films to be attributed to the chitosan (Kong et al., 2010) rather than to the $\mathrm{pH}$.

\subsection{Preparation of Films}

Films were prepared by cold casting method placing the FFS over rectangular teflon molds and stored at $5 \pm 1^{\circ} \mathrm{C}$ for 10 days, obtaining flat and translucent films with a uniform thickness of $250 \pm 5 \mu \mathrm{m}$ measured with a micrometer (Mitutoyo, Japan). The films were then cut into $70 \mathrm{~mm}$ long and $10 \mathrm{~mm}$ wide strips. Subsequently, the films were dried at $20^{\circ} \mathrm{C}$ and $0 \%$ relative humidity (RH) with $\mathrm{P}_{2} \mathrm{O}_{5}$ for 7 days and then equilibrated under different $\mathrm{RH}$ using saturated salt solutions $\left(\mathrm{MgCl}_{2}\right.$ at $33 \% \mathrm{RH}$ and $\mathrm{KCl}$ at $\left.85 \% \mathrm{RH}\right)$ (Greenspan, 1977) in order to obtain samples in both the glassy and the rubbery states, respectively. The moisture content was determined gravimetrically at $105^{\circ} \mathrm{C}$ after $24 \mathrm{~h}$.

\subsection{Glass Transition Temperature (Tg)}

In order to confirm that the state of the films were glassy and rubbery it was necessary to measure the glass transition temperature (Tg) of each film. The Tg of each film was evaluated by differential scanning calorimetry (Diamond DSC, Perkin Elmer, USA), previously calibrated using indium (melting onset temperature $156.6 \pm 1.56^{\circ} \mathrm{C}, \Delta \mathrm{H}=28.6 \pm 1 \mathrm{~J} / \mathrm{g}$ ). Approximately $20 \mathrm{mg}$ of each film (by duplicate) was placed in $30-\mu \mathrm{l}$ aluminum pans and then hermetically sealed. Thermograms were obtained in the temperature range from -70 to $120^{\circ} \mathrm{C}$ at a heating rate of $10^{\circ} \mathrm{C} / \mathrm{min}$ and a cooling rate of $40^{\circ} \mathrm{C} / \mathrm{min}$, under dry nitrogen purge $(50 \mathrm{~mL} / \mathrm{min})$. Tg values, defined as the midpoint of the change in heat capacity, were calculated from the second DSC heating scan using the instrument's software (Pyris Software v 9.0.2. USA).

\subsection{Moisture Sorption Kinetic}

Taking into account that the films in different initial state was putting in contact with liquid broth and agar to measure antimicrobial activity, it was important to measure the kinetic of moisture absorption from the culture medium to the films, which was assessed simulating the microbial incubation at $37^{\circ} \mathrm{C}$. Pieces of each film $\left(1 \mathrm{~cm}^{2}\right)$ was placed onto the agar plates by triplicates, and their weight was followed each $10 \mathrm{~min}$ until $90 \mathrm{~min}$. Moisture sorption rate (MAR) was obtained from the slope obtained using linear regression between the \% water absorbed by the film during time.

\subsection{Antimicrobial Activity of FFS and Films}

The antimicrobial activity of the FFS and the films was evaluated against E. coli (ATCC 25922), Listeria monocytogenes (ISP 65-08) and Salmonella typhimurium (ISP Ty2). Bacteria were obtained from the ISP (Health Public Institute, Chile). The selection of the bacteria used is based on the common meat product contaminants (D’Aoust, 1991; Farber \& Daley, 1994; Martin \& Beutin, 2011).

\subsubsection{Culture Preparation}

The bacteria were stored at $-20^{\circ} \mathrm{C}$ in Mueller Hinton broth with $20 \%$ skim milk until use. Each bacterium was previously grown in Mueller Hinton broth (DIFCO, France) at $37^{\circ} \mathrm{C}$ overnight. This culture served as the inoculums for the microbiological studies, these colony-forming units (CFU) counts were accurately and reproducibly obtained by absorbance value measured by optical density at $625 \mathrm{~nm}$ on a spectrophotometer (Shimadzu UVmini-1240, Japan) using the Mc Farland factor $=0.05$ (Center for Disease Control and Prevention 
(CDCP) \& World Health Organization (WHO), 2003) and diluted starting with a final concentration of each bacterium of $1 \times 10^{5}(\mathrm{CFU}) / \mathrm{mL}$.

\subsubsection{Agar Diffusion Method}

Antibacterial activity tests of FFS and films were performed using an agar diffusion method according to Pranoto et al. (2005). FFS ( $30 \mu \mathrm{L})$ and films $\left(1 \mathrm{~cm}^{2}\right.$ pieces) were placed on Mueller Hinton (Merck, Germany) agar plates, which had been previously seeded homogenously in the agar medium with $1 \times 10^{5} \mathrm{CFU} /(\mathrm{mL}$ of agar) of each bacterial species. The films were then incubated at room temperature $\left(\sim 20^{\circ} \mathrm{C}\right)$ for $5,10,15$ and 20 min and immediately removed, to reduce the diffusion of water to the films.

Later, both agar plates containing FFS drops and the films (which were incubated and removed) were incubated at $37^{\circ} \mathrm{C}$ for $24 \mathrm{~h}$ and examined for inhibition halos. The appearance of a clean area under the FFS drops or under the film zones had been previously placed was an indication of positive antimicrobial activity. Each assay was performed in triplicate.

\subsubsection{Bacterial Growth Kinetics}

The growth kinetics of each bacterial species in the FFS studied was assessed taking into account that the final volume of each tube was $10 \mathrm{~mL}$, where containing i) a concentrated broth $(1 \mathrm{~mL})$ in order to obtain the concentration in the final volume of $10 \mathrm{~mL}(21 \mathrm{~g} / \mathrm{L})$; ii) $1 \mathrm{~mL}$ of each bacteria in order to obtain the concentration of $1 \times 10^{5} \mathrm{CFU} / \mathrm{mL}$ in the final volume of $10 \mathrm{~mL}$; iii) $8 \mathrm{~mL}$ of each FFS or distilled water as control of bacteria growth in nutrient medium. Then, $300 \mu \mathrm{L}$ of each sample was placed in immunoassay wells (Nunc) and incubated at $37^{\circ} \mathrm{C}$ in a Multiscan (Labsystem model 352), logging optical density data at $400 \mathrm{~nm}$ each hour for $24 \mathrm{~h}$ using the ASCENT v.2.6 software (Finland). The results were expressed as mean value with their corresponding standard deviation from sixfold.

\subsubsection{Bacterial Viability Method from Films}

A novelty experimental design is described to measure the bacterial viability percentage from films instead from liquid suspensions containing the antimicrobial agent.

In order to obtain hydrated films with high molecular mobility and promote the diffusion chitosan into the broth, a piece of each film $\left(1 \mathrm{~cm}^{2}\right)$ was put in tubes containing $4.5 \mathrm{~mL}$ of Mueller Hinton broth $(21 \mathrm{~g} / \mathrm{L})$ and incubated at $37^{\circ} \mathrm{C}$ for $24 \mathrm{~h}$. Subsequently, bacteria were added at a concentration of $1 \times 10^{3} \mathrm{CFU} /(\mathrm{mL}$ of broth) and incubated at $37^{\circ} \mathrm{C}$ for $12,24,36$ and $48 \mathrm{~h}$. Later, an aliquot of the broth $(100 \mu \mathrm{L})$ was then placed on a Petri plate containing Mueller Hinton agar and colonies were counted after incubation at $37^{\circ} \mathrm{C}$ for $24 \mathrm{~h}$.

In an attempt to assess the diffusion of chitosan from the gelatine films to the liquid medium, 50, 100 and $200 \mu \mathrm{L}$ aliquots of Mueller Hinton broth previously in contact with the hydrated films (without the addition of bacteria) were placed on agar plates inoculated with E. coli and incubated at $37^{\circ} \mathrm{C}$ for $24 \mathrm{~h}$. The objective was to assess the diffusion of chitosan to the liquid medium.

The results could be expressed as bacterial viability percentage and inhibition growth percentage.

\subsection{Statistical Analysis}

All antimicrobial experiments were carried out in triplicate reporting the values of mean and standard deviation. The results were analyzed statistically by one-way analysis of variance (ANOVA) using the Graph Pad Prism software (v4). Differences between pairs of means were assessed on the basis of confidence intervals $(p<0.05)$ using the Bonferroni post-test.

\section{Results and Discussion}

\subsection{Glass Transition Temperature (Tg)}

The measurement of Tg showed that both gelatin pure films and each gelatin-chitosan films equilibrated at 33 and $85 \% \mathrm{RH}$ were in the glassy and a rubbery state, respectively at the experimental temperature $\left(20^{\circ} \mathrm{C}\right)$, as shown in Figure 1. Although the films equilibrated at $85 \% \mathrm{RH}$ obtained high moisture contents ( $>40 \%$ dry weight basis, d.w.b.) due to the hygroscopic nature of chitosan, the DSC thermograms did not show transitions associated with the melting of ice at temperatures near $0^{\circ} \mathrm{C}$ (data not shown), indicating that free water is not present in the samples and a reduction of water availability for microorganism growth in the rubbery state of the film.

According to the results of Gomez-Estaca et al. (2011) and Suyatma, Tighzert and Copinet (2005), a single glass transition temperature is observed on the DSC thermograms, showing good miscibility of bovine and fish skin gelatin with chitosan. In this work, the $\mathrm{Tg}$ value of the bovine $-0.5 \% \mathrm{w} / \mathrm{w}$ chitosan film equilibrated at $85 \% \mathrm{RH}$ and $20^{\circ} \mathrm{C}$ was $\sim-1{ }^{\circ} \mathrm{C}$ (rubbery state). $\mathrm{Tg}$ of the same film increased to $\sim 37^{\circ} \mathrm{C}$ when was equilibrated at $33 \% \mathrm{RH}$ (glassy 
state). Therefore, the $\mathrm{Tg}$ values of the gelatin-chitosan films decreased in comparison with gelatin films as the concentration of chitosan increased, which is associated with the high hygroscopicity of this biopolymer that increase the water content of gelatin-chitosan films, diminishing Tg values by water plasticization effect. However, although this phenomena, the glassy and rubbery state was obtained at each relative humidity by all the evaluated samples (with and without chitosan).

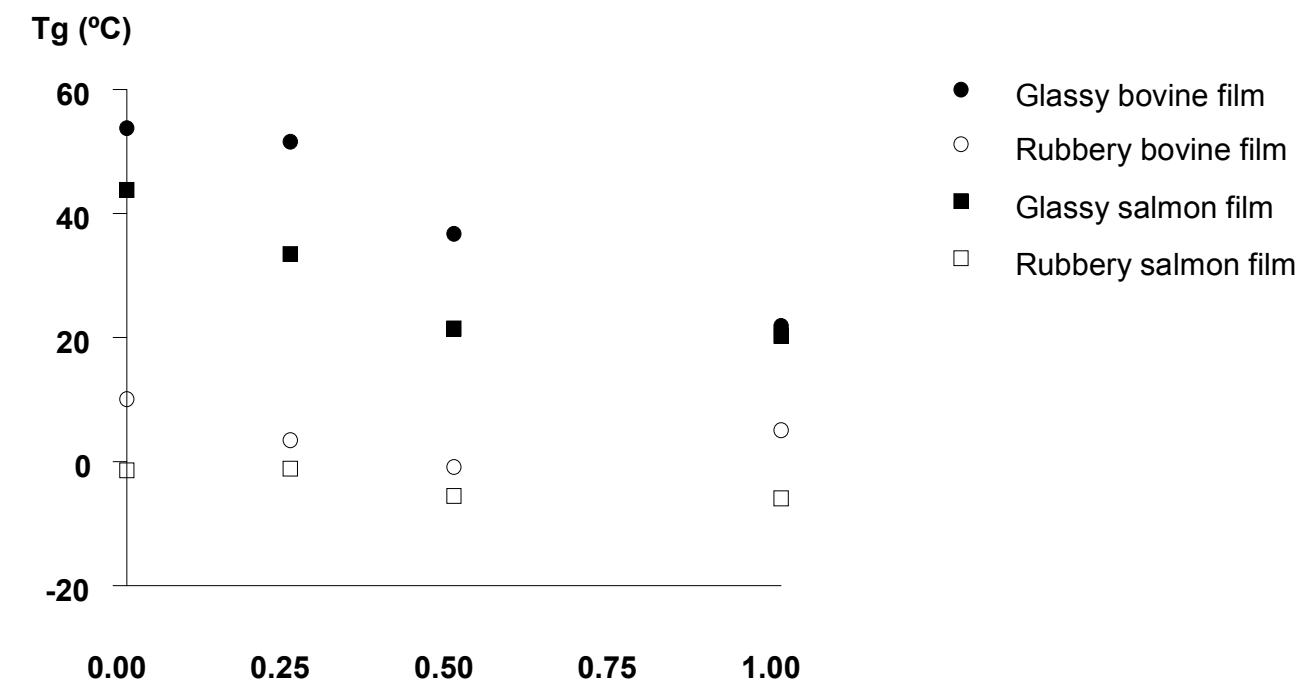

$[\mathrm{Ch}](\% \mathrm{w} / \mathrm{w})$

Figure 1. Glass transition temperature $(\mathrm{Tg})$ in order to chitosan concentration [Ch]

\subsection{Antimicrobial Properties of Suspensions}

As the solvent of chitosan, acetic acid with a concentration over $200 \mathrm{ppm}(0.02 \% \mathrm{w} / \mathrm{w})$ had antibacterial activity against $E$. coli at pH 5.4 (Liu et al., 2006). These authors showed that chitosan of low molecular weight over 200 ppm $(0.02 \% \mathrm{w} / \mathrm{w})$ had also antibacterial activity. Although, some studies were performed using acetic acid concentration over this value and in a high proportion comparing to chitosan concentration, such as 1:50 (Devegliehere et al., 2004) and 1:3 (Gómez-Estaca et al., 2011), the authors attributed that the antimicrobial activity observed was performed by only chitosan. Therefore, the antibacterial properties observed will be a combination of the effect of both chitosan and acetic acid, in according to Liu et al. (2006).

As expected, the FFS for both gelatins with chitosan showed antibacterial properties against all the bacteria studied. As chitosan concentration increased in the FFS, the inhibition zone area became cleaner but the diameter of the inhibitory halo remained constant (Figure 2). The reduced inhibitory activity of FFS may be explained by the restricted diffusion phenomenon of chitosan from the gelatin matrix due to the interaction with the components of the films (gelatins), which is consistent with results previously reported by other authors (Coma, 2002; Pranoto et al., 2005). 

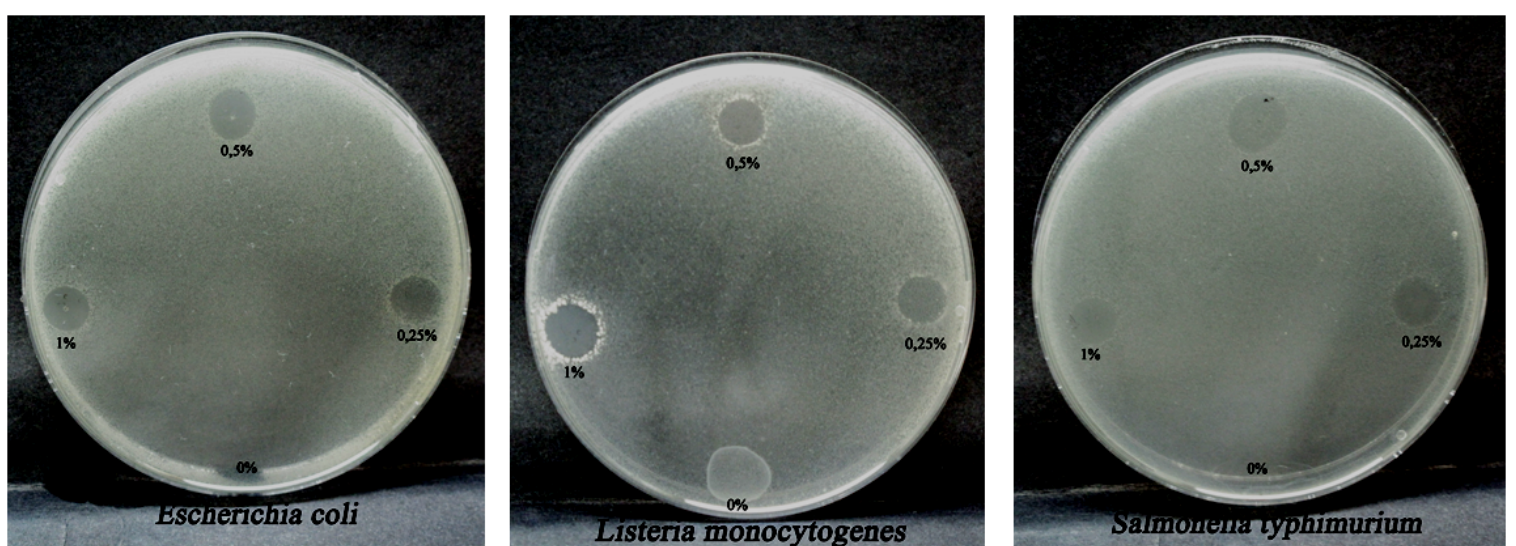

Figure 2. Results of agar diffusion method using $30 \mu \mathrm{l}$ of each film-forming suspensions (FFS) in order to chitosan concentration $(0 ; 0.25 ; 0.5$ and $1 \% \mathrm{w} / \mathrm{w})$ against (a) E. coli, (b) L. monocytogenes, and (c) S. typhimurium

In order to confirm the antimicrobial effectiveness of the FFS, the growth kinetics of each bacterium was assessed in a liquid medium. The results obtained for bovine and salmon gelatin FFS are presented in Figure 3. The growth kinetics of $E$. coli was significantly affected by all FFS, including bovine gelatin FFS (control), which reduced the growth kinetics by $38.0 \%$ compared to pure nutrient medium (Figure 3a). This result was also seen for $S$. thypimurium ( $40 \%$ lower growth rate than control, Figure 3c). A possible explanation of this result (antimicrobial activity of gelatin pure) could be related to the presence of oligopeptides with antimicrobial properties such as amino groups present in the polymer chain as a result of the partial hydrolysis of commercial gelatin, as reported previously by Pereda et al. (2011). All the chitosan concentrations used in bovine-chitosan FFS inhibited $100 \%$ of E. coli growth (Figure 3a). However, only the presence of $1 \% \mathrm{w} / \mathrm{w}$ of chitosan (highest concentration used in this study) presents in bovine FFS inhibited $100 \%$ of the growth of L. monocytogenes and S. thyphimurium after $24 \mathrm{~h}$ (Figures $3 \mathrm{~b}$ and c). It should be noted that concentrations lower than $1 \% \mathrm{w} / \mathrm{w}$ of chitosan showed growth recovery from viable cells in the liquid medium with the time incubation, indicating a bacteriostatic effect of chitosan against these last two bacteria. 

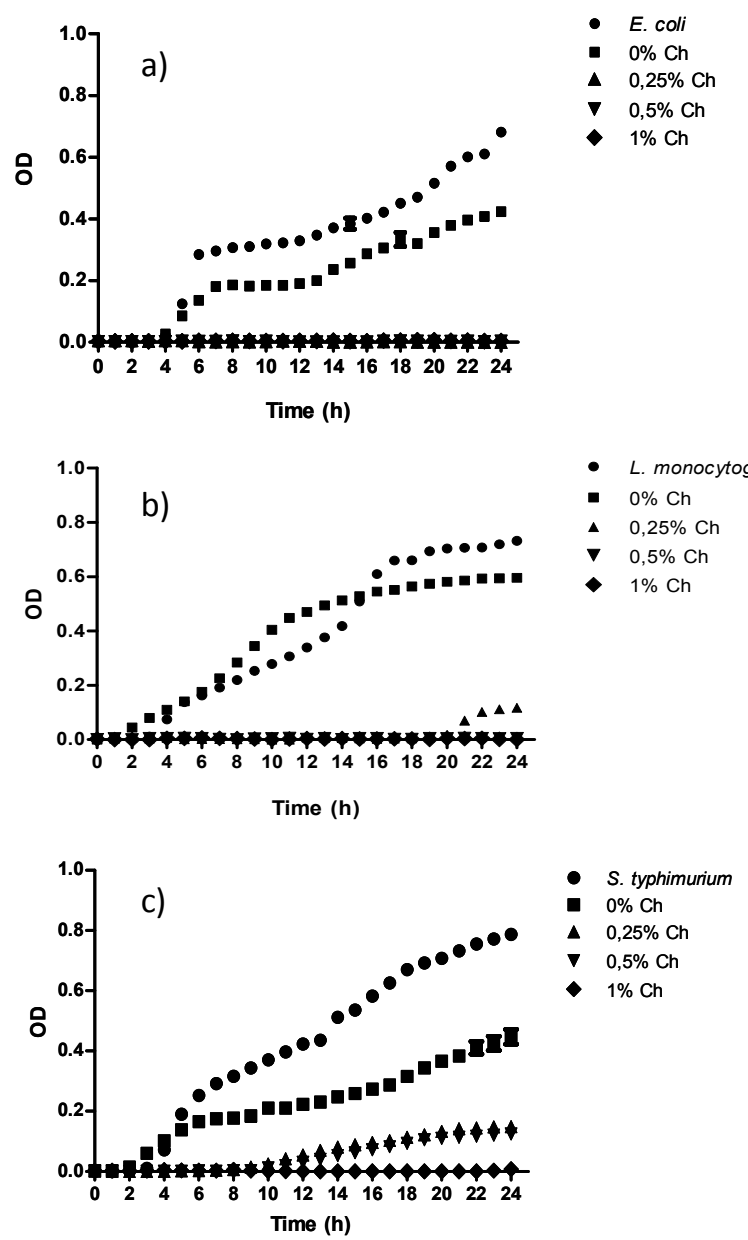

- $0 \% \mathrm{Ch}$

- $0,25 \% \mathrm{Ch}$

v $0,5 \% \mathrm{Ch}$

- $1 \% \mathrm{Ch}$

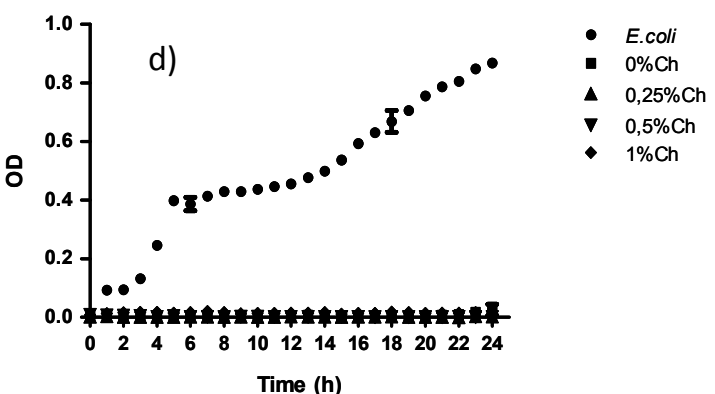

- L. monocytogenes
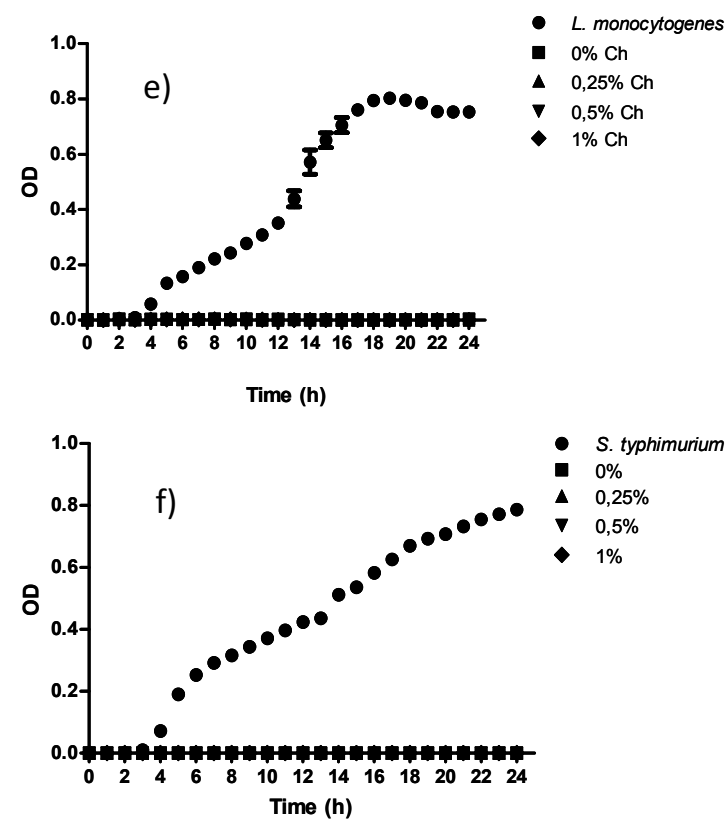

Figure 3. Bacterial growth kinetics in presence of $(a, b, c)$ bovine and $(d, e, f)$ salmon gelatin film-forming suspension at different chitosan $(\mathrm{Ch})$ concentrations $(0 ; 0.25 ; 0.5$ and $1 \% \mathrm{w} / \mathrm{w})$ for a) and d) Escherichia coli; b) and e) Listeria innocua; c) and f) Salmonella typhimurium. OD: optical density

It is interesting to note that pure bovine gelatin FFS also affected the kinetics and typical growth profile of $L$. monocytogenes during the first 7-15 h of incubation, as seen in Figure 3b, where the initial bacterial growth was higher than in nutrient medium, indicating a particular biological activity of $L$. monocytogenes in gelatin, which it was used as nutrient medium, in according to Celis, Enrione \& Matiacevich (2011). This result indicates the necessity of the addition of antimicrobial agents in edible films based on hydrocolloids such as gelatin.

Whereas, bovine gelatin FFS containing chitosan were more effective $(\mathrm{p}<0.05)$ against $E$. coli even with the lower concentration used $(0.25 \% \mathrm{w} / \mathrm{w})$ compared to L. monocytogenes and S. typhimurium, indicating the most chitosan-resistant of the bacteria studied.

The bacterial growth in presence of salmon gelatin-chitosan FFS is presented in Figure 3 (d, e and f), where all chitosan concentrations used inhibited the growth of all bacteria, including the pure salmon gelatin FFS without chitosan. This result may also be associated to oligopeptides with antimicrobial properties (Pereda et al., 2011), which could be present in the sample due to the hydrolysis of salmon gelatin during their laboratory extraction process.

\subsection{Antimicrobial Effect of Chitosan in Films}

No inhibition zone was seen when the agar diffusion method was applied to each film and bacteria (data not shown) under the tested conditions. This is an indication that the chitosan could not diffuse from the film to the agar, even though the film matrix had significant molecular mobility (rubbery state), supporting the interaction between chitosan and the gelatin matrix. Pranoto et al. (2005) reported that chitosan films at $1 \% \mathrm{w} / \mathrm{w}$ did not show an inhibitory effect against E. coli, S. aureus, S. typhimurium, L. monocytogenes and B. cereus using the agar 
diffusion method, and the authors suggested that chitosan active sites must be available to inhibit microorganisms if integrated in a solid matrix such as films, which was associated with a reduced availability of $\mathrm{R}_{-}-\mathrm{NH}_{3}{ }^{+}$that could interact with the membrane cells of various microorganisms (Coma, 2002; Pereda et al., 2011). Devlieghere et al. (2004) also suggested that when chitosan is combined with a protein, the influence of the protein is mainly dependent on the $\mathrm{pH}$ of the medium. If the $\mathrm{pH}$ is increased to a value above the isoelectric point of the protein (as in this study), the antimicrobial activity of chitosan is inhibited, due to there is competition for the positive charges on chitosan between the negative charges on the protein isolate and the negative charges on the cell surface of the microorganism.

The antimicrobial properties of the gelatin films were tested only with E. coli in the presence of the highest concentration of chitosan $(1 \% \mathrm{w} / \mathrm{w})$. The results are shown in Table 1, indicating that no significant differences $(\mathrm{p}>0.05$ ) were found between 24,36 and $48 \mathrm{~h}$ of incubation under same conditions. Furthermore, it is important to note that the gelatin pure films had some inhibitory effect on bacterial growth in the nutrient medium (Table 1), being more significant by the gelatin extracted from salmon. This effect was also shown by the FFS previously reported in this paper (Figure 3).

Table 1 shows the effect of chitosan in the films in the glassy and rubbery states on the growth of $E$. coli compared to the inhibition caused by pure gelatin; therefore, the reported data were attributed to the presence of the branched carbohydrate. Statistical differences $(\mathrm{p}<0.05)$ were found in the inhibition percentage between the films above and below Tg until $12 \mathrm{~h}$ of incubation, which was more significant in salmon gelatin-chitosan (38.3\%) than in bovine gelatin-chitosan films (5.4\%).

Table 1. Inhibition growth percentage of Escherichia coli in the presence of bovine gelatin pure film and 1\% w/w chitosan-gelatin films due to only by the chitosan antibacterial activity, in both initial glassy and rubbery state of the film matrix

\begin{tabular}{cccc}
\hline Sample & Initial structural state & \% inhibition growth in incubation time \\
\cline { 3 - 4 } & - & $12 \mathrm{~h}$ & $24-48 \mathrm{~h}$ \\
\hline $\begin{array}{c}\text { E. coli in nutrient } \\
\text { medium (control) }\end{array}$ & Glassy state & 0 & 0 \\
Bovine gelatin- pure & Rubbery state & $2.7 \pm 2.5$ & $14.5 \pm 2.0$ \\
film & Glassy state & $17.4 \pm 1.5$ & $68.0 \pm 2.6$ \\
Bovine gelatin- & Rubbery state & $12.0 \pm 3.2$ & $57.5 \pm 2.5$ \\
chitosan film & Glassy state & $6.7 \pm 3.0$ & $20.6 \pm 4.0$ \\
Salmon gelatin-pure & Rubbery state & $8.3 \pm 3.0$ & $14.6 \pm 3.7$ \\
film & Glassy state & $51.0 \pm 3.0$ & $67.0 \pm 1.0$ \\
Salmon & Rubbery state & $7.6 \pm 3.0$ & $57.5 \pm 2.5$ \\
\hline
\end{tabular}

Therefore the molecular mobility of the matrix affected the antimicrobial activity of gelatin-chitosan films. In the rubbery state, the amonio groups $\left(\mathrm{R}_{-} \mathrm{NH}_{3}{ }^{+}\right)$of chitosan have greater mobility but they are not sufficiently exposed for growth inhibition (Table 1). The differences observed were minimal between salmon and bovine gelatin-chitosan films as the incubation time increased (24-48 h). However, when comparing only effect caused by chitosan in films until $12 \mathrm{~h}$ of incubation, the highest percentage of bacterial viability was obtained in salmon gelatin-chitosan film (50\%) comparing to the bovine gelatin-chitosan films (18.5\%), both in the glassy state.

This differences observed by the initial mobility (glassy and rubbery) state could be attributed to the differences observed in the moisture uptake of the films, where the moisture uptake rate was $1.82 \pm 0.02 \%$ water adsorbed $/ \mathrm{min}$ in the glassy state comparing to the $0.52 \pm 0.1 \%$ water adsorbed $/ \mathrm{min}$ in the rubbery state for both gelatins, indicating a moisture uptake rate of $70 \%$ higher in glassy state than in rubbery state.

Bacterial viability of the film control in liquid media showed that there was no inhibition of bacterial growth by diffusion of chitosan, regardless of the incubation time of the film (12-24 h) and the volume (50-100 $\mu \mathrm{L})$ used to measure total viable colony count. Pure chitosan can migrate to agar (Dutta et al., 2009; Pranoto et al., 2005). 
However, studies of mixtures of other hydrocolloids show that they are not capable of migrating due to interaction between them (Coma, 2002; Pereda et al., 2011). The results obtained confirmed that chitosan is not able to migrate from the film to the nutrient broth and agar, suggesting an interaction with the gelatin matrix. Chitosan increases the molecular mobility in the films by its hygroscopic nature, in other words by attracting more water, allowing its $\mathrm{R}^{-\mathrm{NH}_{3}}{ }^{+}$groups to act on bacteria as greatly reported in the literature (Coma, 2002; Pereda et al., 2011; Pranoto et al., 2005).

\section{Conclusions}

Antimicrobial properties of both film-forming suspensions and films tested against E. coli, L. monocytogenes and S. typhimurium showed that chitosan has antimicrobial activity but was not able to diffuse from the gelatin matrix. Therefore, their activity is effective against surface growth without the migration of the active agents.

Antimicrobial activity increased as chitosan concentration increased, and it was most effective against Escherichia coli. In contrast, films did not present inhibition effect using the agar diffusion method, and the viability assay only presented some inhibition at $1 \%$ chitosan concentrations against $E$. coli. However, significant differences $(p<0.05)$ in inhibition growth between films of both gelatins equilibrated above and below $\mathrm{Tg}$ were obtained until $12 \mathrm{~h}$ of incubation related to the moisture uptake ratio, with important differences affected by the molecular mobility in salmon gelatin films.

The results showed that the molecular mobility of the surrounding matrix has the largest influence on the antimicrobial activity of chitosan, decreasing its effect due to the unique cationic character of the matrix, which has the potential to bind with food components such as proteins. This factor is a good indication that the promising results obtained in suspensions are not necessarily applicable to systems formed by other biopolymers at intermediate moisture contents that resemble real food systems. Future studies should be aimed at improving the understanding of the interactions of edible coatings with functional components in terms of the chemistry and the physics involved, in order to properly design formulations to extend the storage time of a fresh food.

\section{Acknowledgments}

The authors acknowledge the support of Salmon Oil S.A., which provided the material, and the financial support of the Bicentennial Grants (PBCT PSD-62 and 79090034) and Fondecyt Projects 11100209, 1110607 and 11080133.

\section{References}

Aider, M. (2010). Chitosan application for active bio-based films production and potential in the food industry: Review. LWT - Food Science and Technology, 43, 837-842. http://dx.doi.org/10.1016/j.lwt.2010.01.021

Celis, D., Enrione, J., \& Matiacevich, S. (2011). Comportamiento de Listeria monocytogenes frente a biopolímeros utilizados en películas comestibles con y sin antimicrobiano. Indualimentos, 13, 92-94.

Center for Disease Control and Prevention (CDCP), \& World Health Organization (WHO). (2003). Manual for the laboratory identification and antimicrobial susceptibility testing of bacterial pathogens of public health importance in the developing world. 209-214

Cha, D. S., \& Chinnan, M. S. (2004). Biopolymer-based antimicrobial packaging: a review. Critical Review in Food Science and Nutrition, 44, 223-237. http://dx.doi.org/10.1080/10408690490464276

Coma, V. (2002). Bioactive packaging technologies for extended shelf life of meat-based products. Meat Science, 78, 90-103. http://dx.doi.org/10.1016/j.meatsci.2007.07.035

D'Aoust, J. Y. (1991). Psychrotrophy and foodborne Salmonella. International Journal of Food Microbiology, 13, 207-215. http://dx.doi.org/10.1016/0168-1605(91)90004-9

Devlieghere, F., Vermeulen, A., \& Debevere, J. (2004). Chitosan: antimicrobial activity, interactions with food components and applicability as a coating on fruit and vegetables. Food Microbiology, 21, 703-714. http://dx.doi.org/10.1016/j.fm.2004.02.008

Diaz, P., Lopez, D., Matiacevich, S., Osorio, F., \& Enrione, J. (2011). State diagram of salmon (Salmo salar) gelatin films. Journal of the Science of Food and Agriculture, 91, 2558-2565. http://dx.doi.org/10.1002/jsfa.4451

Dutta, P. K., Dutta, J., \& Tripathi, V. (2004). Chitin and chitosan: Chemistry, properties and applications. Journal

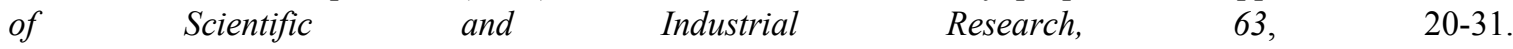
http://nopr.niscair.res.in/bitstream/123456789/5397/1/JSIR\%2063\%281\%29\%2020-31.pdf

Dutta, P. K., Tripathi, S., Mehrotra, G. K., \& Dutta, J. (2009). Perspectives for chitosan based antimicrobial films in food applications. Food Chemistry, 114, 1173-1182. http://dx.doi.org/10.1016/j.foodchem.2008.11.047 
Fan, M., Hu, Q., \& Shen, K. (2009). Preparation and structure of chitosan soluble in wide $\mathrm{pH}$ range. Carbohydrate Polymers, 78, 66-71. http://dx.doi.org/10.1016/j.carbpol.2009.03.031

Farber, J. M., \& Daley, E. (1994). Presence and growth of Listeria monocytogenes in naturally-contaminated meats. International Journal of Food Microbiology, 22, 33-42. http://dx.doi.org/10.1016/0168-1605(94)90005-1

Fernández-Saiz, P., Lagaron, J. M., \& Ocio, M. J. (2009). Optimization of the biocide properties of chitosan for its application in the design of active films of interest in the food area. Food Hydrocolloids, 23, 913-921. http://dx.doi.org/10.1016/j.foodhyd.2008.06.001

Gómez-Estaca, J., López de Lacey, A., López-Caballero, M. E., Gómez-Guillén, M. C., \& Montero, P. (2010). Biodegradable gelatin-chitosan films incorporated with essential oils as antimicrobial agents for fish preservation. Food Microbiology, 27, 889-896. http://dx.doi.org/10.1016/j.fm.2010.05.012

Gómez-Estaca, J., Gómez-Guillén, M. C., Fernández-Martín, F., \& Montero, P. (2011). Effects of gelatin origin, bovine-hide and tuna-skin, on the properties of compound gelatin-chitosan films. Food Hydrocolloids, 25, 1461-1469. http://dx.doi.org/10.1016/j.fm.2010.05.012

Greenspan, L. (1977). Humidity fixed points of binary saturated aqueous solutions. Journal of Research of the National Bureau of Standards, 81 A, 89-96.

Jamilah, B., Harvinder, K. (2002). Properties of gelatins from skins of fish-black tilapia (Oreochromis mossambicus) and red tilapia (Oreochromis nilotica). Food Chemistry, 77, 81-84. http://dx.doi.org/10.1016/S0308-8146(01)00328-4

Karim, A. A., \& Bhat, R. (2009). Fish gelatin: properties, challenges, and prospects as an alternative to mammalian gelatins. Food Hydrocolloids, 23, 563-576. http://dx.doi.org/10.1016/j.foodhyd.2008.07.002

Kong, M., Chen, X. G., Xing, K., \& Park, H. J. (2010). Antimicrobial properties of chitosan and mode of action: A state of the art review. International Journal of Food Microbiology, 144, 51-63. http://dx.doi.org/10.1016/j.ijfoodmicro.2010.09.012

Liu, N., Chen, X. G., Park, H. J., Liu, Ch G., Liu, Ch S., Meng, X. H., \& Yu, L. Y. (2006). Effect of MW and concentration of chitosan on antibacterial activity of E. coli. Carbohydrate Polymers, 64, 60-65. http://dx.doi.org/10.1016/j.carbpol.2005.10.028

Martin, A., \& Beutin, L. (2011). Characteristics of Shiga toxin-producing Escherichia coli from meat and milk products of different origins and association with food producing animals as main contamination sources. $\begin{array}{llllll}\text { International Journal of } & \text { Food }\end{array}$ http://dx.doi.org/10.1016/j.ijfoodmicro.2011.01.041

Official Methods of Analysis (OMA). (1975). Association of Official Analytical Chemists (12en ed.). Washington, DC.

Pereda, M., Ponce, A., Marcovich, N., Ruseckaite, R., \& Martucci, J. (2011). Chitosan-gelatin composites and bi-layer films with potential antimicrobial activity. Food Hydrocolloids, 25, 1372-1381. http://dx.doi.org/10.1016/j.foodhyd.2011.01.001

Pranoto, Y., Rakshit, S. K., \& Salokhe, V. M. (2005). Enhancing antimicrobial activity of chitosan films by incorporating garlic oil, potassium sorbate and nisin. LWT - Food Science and Technology, 38, 859-865. http://dx.doi.org/10.1016/j.lwt.2004.09.014

Qin, C., Li, H., Xiao, Q., Liu, Y., Zhu, J., \& Du, Y. (2006). Water-solubility of chitosan and its antimicrobial activity. Carbohydrate Polymers, 63, 367-374. http://dx.doi.org/10.1016/j.carbpol.2005.09.023

Suyatma, N., Tighzert, N., \& Copinet, A. (2005). Effects of hydrophilic plasticizers on mechanical, thermal and surface properties of chitosan films. Journal of Agricultural and Food Chemistry, 53, 3950-3957. http://dx.doi.org/10.1021/jf048790

Valencia-Chamoro, S. A., Palou, L., Del Rio, M. A., \& Pérez-Gago, M. B. (2011). Antimicrobial edible films and coatings for fresh and minimally processed fruits and vegetables: a review. Critical Reviews in Food Science and Nutrition, 51, 872-900. http://dx.doi.org/10.1080/10408398.2010.485705 